\title{
Uji Validitas Konstruk Work Role Performance pada Karyawan di Indonesia
}

\author{
Bella Saviera, Hery Susanto, Anissa L. Kadiyono \\ Program Studi Magister Psikologi Profesi, Fakultas Psikologi, Universitas Padjadjaran, Bandung
}

Abstrak. Kinerja karyawan merupakan hal yang penting bagi keberhasilan perusahaan. Dalam mencapai tujuannya, perusahaan akan menghadapi banyak tantangan. Hal tersebut dapat diatasi dengan beberapa cara, salah satunya yakni dengan meningkatkan kinerja karyawan. Oleh karena itu, penting untuk mengukur kinerja peran karyawan di Indonesia. Alat ukur work role performance pertama kali dikembangkan di Australia pada tahun 2007 dan belum pernah diadaptasi untuk populasi di Indonesia. Penelitian ini bertujuan untuk mengevaluasi validitas dan reliabilitas alat ukur work role performance dalam bahasa Indonesia. Aiken's V digunakan untuk mengevaluasi validitas konten alat ukur. Baik Classical Test Theory (CTT) dan analisis Rasch digunakan untuk mengevaluasi realibilitas dari alat ukur. Partisipan dalam penelitian ini adalah karyawan sebanyak $370(n=370)$ yang diambil dengan menggunakan teknik pengambilan sampel insidental. Hasil penelitian menunjukkan bahwa Aiken's $V$ sebesar .87 dan .91 yang berarti butir yang diadaptasi relevan untuk mengukur konstruk. Skala yang diadaptasi menunjukkan bahwa reliabel dengan Alpha Cronbach sebesar .936 serta Rasch's model sebesar 87 dan .98. Pada hasil Confirmatory Factor Analysis (CFA), model fit dapat diterima (RMSEA = $.08, \mathrm{CFI}=.96$ ) yang menunjukkan bahwa data sesuai dengan hipotesis penelitian yaitu tidak ada perbedaan antara matriks Ó dan matriks S.

Kata Kunci: karyawan, validitas konstruk, work role performance

\section{The Construct Validity Test of Work Role Performance on Employee in Indonesia}

Abstract. Employee performance is critical to the overall success of the company. In achieving their goals, companies will face many challenges. This can be overcome in several ways, one of which is by improving employee performance. Therefore, it is important to measure the role performance of the employee in Indonesia. The work role performance scale was first developed in Australia in 2007 and have not been adapted for the Indonesian population. This study intends to evaluate the validity and the reliability of the Indonesian version of the work role performance scale. Aiken's V formula was used to evaluate the content validity of the scale. Both Classical Test Theory (CTT) and Rasch analyses were employed to evaluate the reliability of the scale. Participants in this study were employees, with a total of $370(n=370)$, collected by using accidental sampling techniques. The results showed Aiken's V of .87 to .91 shows that points of the adapted scale were relevant to measure the construct. The adapted scale was found reliable with Cronbach's alpha of .936 and Rasch's person and point reliability were .87 and .98. In Confirmatory Factor Analysis (CFA) results, the model fit was acceptable (RMSEA $=.08, \mathrm{CFI}=$ .96) shows that the data fit the hypothesized model, there is no difference between the Ó dan $\mathrm{S}$ matrix.

Keywords: content validity, employee, work role performance

Korespondensi: Bella Saviera. Email: bella20008@mailunpad.ac.id 
Perusahaan yang bergerak di bidang industri, manufaktur maupun jasa akan berusaha dengan sebaik mungkin untuk mencapai tujuan yang telah ditetapkan. Upaya yang dapat dilakukan untuk mencapai tujuan tersebut tidak hanya dapat ditunjang oleh keunggulan teknologi, dana operasi, serta sarana dan prasarana yang ada, melainkan terdapat aspek yang lebih penting, yaitu sumber daya manusia karena karyawan merupakan aset yang berharga bagi perusahaan dan berperan penting dalam pengelolaan suatu perusahaan (Fulmer \& Ployhart, 2014).

Keberadaan dari seorang karyawan yang merupakan sebagai sumber daya manusia merupakan aspek yang terpenting bagi terwujudnya tujuan dari organisasi. Peranan sumber daya manusia menjadi bertambah penting ketika perusahaan menghadapi era globalisasi yang penuh dengan tantangan. Dengan demikian, setiap organisasai perlu memperhatikan pengelolaan sumber daya manusia. Apabila perusahaan gagal membentuk sumber daya manusia, perusahaan akan mengalami kerugian berupa tidak tercapainya tujuan organisasi (Priyono, 2010).

Salah satu faktor yang berguna untuk meningkatkan sumber daya manusia dalam bekerja adalah pengukuran terhadap kinerja karyawan dalam bekerja (Priyono, 2010). Melalui pengukuran kinerja karyawan, perusahaan akan dapat mengelola organisasinya secara optimal. Performance karyawan merupakan masalah utama yang harus diperhatikan oleh suatu perusahaan. Perusahaan akan mengalami berbagai rintangan sebelum mencapai sebuah keberhasilan. Hal tersebut dapat ditunjang dengan meningkatkan kinerja karyawan (Fulmer \& Ployhart, 2014).

Secara tradisional, performance dievaluasi dalam kaitannya dengan keahlian seseorang dalam melaksanakan tugas-tugas yang ada. Pada perkembangan selanjutnya, Murphy \& Jackson (1999) menyatakan bahwa pekerjaan yang ditentukan dengan baik merupakan salah satu perilaku yang berkontribusi dalam pencapaian tujuan sebuah organisasi. Dalam era industri 4.0, ciri pekerjaan yang cepat berubah menuntut karyawan untuk memiliki adaptive performance agar berhasil dalam memenuhi tuntutan tugas yang baru atau yang diubah (Jundt et al., 2015). Hal tersebut menunjukkan bahwa model kinerja tradisional yang bersifat statis perlu ditambah dengan menyertakan "responsive terhadap perubahan dalam pekerjaan". Hal tersebut kerap terjadi di Indonesia. Dengan demikian, adaptive performance merupakan hal yang perlu dimiliki oleh setiap karyawan.

Pada awalnya, perkembangan teori work role performance diawali oleh role theory yang merupakan pendekatan penting dalam upaya menggambarkan tanggung jawab kerja dalam peran serta mencakup konteks organisasi dan perilaku kerja seorang individu. Role theory merupakan teori yang menggambarkan organisasi sebagai "sistem perilaku yang interdependen" (Katz \& Kahn, 1978). Akan 
tetapi, penelitian mengenai role theory belum memasukkan konteks organisasi. Selain itu, role theory juga tidak digunakan untuk menggambarkan dimensi dari model prestasi kerja.

Dalam role theory belum terdapat kerangka teoretis yang digunakan untuk membedakan dan mengintegrasikan berbagai konstruksi yang dapat menggambarkan kinerja individu dan hubungannya dengan efektivitas organisasi. Hal tersebut melatarbelakangi pengembangan model baru dalam kinerja peran kerja. Pengembangan model baru tersebut mengusulkan untuk membentuk dan membatasi perilaku di dalam organisasi agar dapat mengidentifikasi ketidakpastian dan ketergantungan yang dapat membuat organisasi menjadi efektif (Griffin et al, 2007).

Ketidakpastian yang dihadapi perusahaan memengaruhi sejauh mana peran kerja dapat diformalkan sehingga menentukan apakah individu dapat efektif dengan hanya mematuhi tuntutan sesuai peran kerja ataukah harus juga beradaptasi terhadap perubahan. Selain itu, ketergantungan juga menentukan sejauh mana peran kerja berkaitan dengan sistem sosial yang lebih luas sehingga menentukan apakah seorang individu dapat efektif dengan hanya mengelola tanggung jawab perannya sebagai individu dalam organisasi atau perlu juga bertindak untuk mendukung konteks sosial organisasi yang lebih luas. Kedua hal tersebut mendorong Griffin et al (2007) mengembangkan alat ukur yang disebut dengan Work Role Performance Scale (WRP-S). Alat ukur tersebut disusun dengan mempertimbangkan konteks ketidakpastian dan ketergantungan yang dihadapi perusahaan.

Di Indonesia, WRP-S belum pernah diadaptasi ke dalam bahasa Indonesia. Pada umumnya, pengukuran performance karyawan di Indonesia dilakukan menggunakan alat ukur job performance atau employee performance. Definisi dari job performance merupakan sebuah tindakan, perilaku dan hasil dari pekerjaan karyawan yang terkait dengan tujuan organisasi (Viswesvaran \& Ones, 2000). Sementara itu, employee performance menurut Shmailan (2016) adalah sebuah tindakan yang dilakukan karyawan dalam melaksanakan pekerjaan yang diberikan oleh perusahaan. Dapat dilihat bahwa job performance ataupun employee performance hanya mengukur tindakan, perilaku, dan hasil pekerjaan karyawan dalam melakukan pekerjaan yang sesuai dengan tujuan dari sebuah organisasi.

Work role performance, menurut Griffin et al (2007), digambarkan melalui klasifikasi perilaku peran yang berkontribusi pada efektivitas di tingkat individu, tim, dan organisasi terhadap tiga perilaku yang berbeda, yaitu proficiency, adaptivity, dan proactivity. Oleh karena itu, peneliti mempertimbangkan bahwa work role performance lebih dapat melihat bagaimana intensi perilaku peran yang dapat memengaruhi tingkat efektivitas dalam organisasi. Hal tersebut juga didukung oleh hasil 
penelitian Griffin et al (2007) yang menunjukkan bahwa terdapat hubungan antara kinerja individu berdasarkan perilaku peran terhadap hasil efektivitas dalam sebuah organisasi. Selain itu, aspek-aspek dari work role performance membantu menjelasakan bagaimana ketidakpastian akan mempengaruhi perilaku yang berkontribusi dalam organisasi. Oleh karena itu, aspek proficiency diperlukan untuk menjaga lingkungan agar tetap stabil. Selain itu, adaptivity dan proactivity yang baik juga diperlukan agar karyawan dapat meningkatkan efektivitas dari sebuah organisasi.

Menurut Griffin et al (2007) terdapat tiga dimensi dalam pengukuran work role performance, yaitu:

1. Proficiency, menggambarkan sejauh mana individu memenuhi persyaratan peran yang telah ditentukan. Dimensi ini terbagi menjadi tiga subdimensi, yaitu Individual task proficiency, yaitu perilaku yang mencerminkan sejauh mana seorang karyawan memenuhi harapan dan persyaratan yang diketahui perannya sebagai individu; Team member proficiency, yaitu perilaku yang mencerminkan sejauh mana individu memenuhi harapan dan persyaratan perannya sebagai anggota tim; dan Organizational member proficiency, yaitu perilaku ini mencerminkan sejauh mana individu memenuhi harapan dan persyaratan perannya sebagai anggota organisasi.
2. Adaptivity, menggambarkan sejauh mana seseorang dapat beradaptasi terhadap perubahan dalam sistem kerja. Individu dapat mengatasi, menanggapi, serta mendukung perubahan yang terjadi di dalam organisasi. Dimensi adaptivity terbagi menjadi tiga subdimensi, yaitu Individual task adaptivity, yaitu perilaku yang mencerminkan sejauh mana individu mengatasi, menanggapi, dan atau mendukung perubahan yang memengaruhi peran mereka sebagai individu; Team member adaptivity, yaitu perilaku yang mencerminkan sejauh mana individu mengatasi, menanggapi dan atau mendukung perubahan yang memengaruhi peran sebagai anggota tim; dan Organizational member adaptivity, yaitu perilaku yang mencerminkan sejauh mana individu mengatasi, menanggapi, dan atau mendukung perubahan yang memengaruhi peran mereka sebagai anggota organisasi.

3. Proactivity, menggambarkan sejauh mana individu mengambil tindakan secara mandiri untuk mengantisipasi atau memulai perubahan dalam sistem kerja atau peran kerja. Dimensi proactivity terbagi menjadi tiga subdimensi, yaitu: Individual task proactivity, yaitu perilaku yang mencerminkan sejauh mana individu terlibat dalam memulai pekerjaan secara pribadi, perilaku yang berorientasi pada masa depan untuk mengubah situasi kerja individu, serta peran kerja individu atau diri 
mereka sendiri; Team member proactivity, yaitu perilaku yang mencerminkan sejauh mana individu terlibat secara mandiri serta perilaku yang mengarah ke masa depan untuk mengubah situasi tim atau cara kerja di dalam tim/kelompok; dan Organizational member proactivity, yaitu perilaku yang mencerminkan sejauh mana individu terlibat secara mandiri serta perilaku yang mengarah ke masa depan untuk mengubah organisasi dan atau cara kerja organisasi.

Pada penelitian Griffin et al (2007) menyarankan bahwa pengukuran konstruk work role performance dilakukan dalam berbagai setting organisasi yang berbeda. Oleh karena itu, peneliti tertarik melakukan adaptasi WRP-S terhadap sebagai salah satu bentuk pengembangan penelitian Griffin et al (2007) yang pengukuran konstruknya baru dilakukan pada dua lingkup organisasi dan terbatas pada analisis external validity. Adapun, hal yang dilakukan oleh peneliti yaitu melakukan adaptasi ke dalam bahasa Indonesia. Menurut Azwar (2015), bahasa dalam alat ukur menjadi salah satu aspek yang penting karena dapat memengaruhi keterbacaan alat ukur. Dengan belum tersedianya alat ukur work role performance berbahasa Indonesia, maka perlu dilakukan adaptasi alat ukur tersebut ke dalam bahasa Indonesia sehingga tersedia alat ukur yang memiliki reliabilitas dan validitas yang baik untuk dapat digunakan pada penelitian yang melibatkan karyawan di Indonesia.
Alat ukur dalam bahasa Indonesia dapat dihasilkan dengan cara mengadaptasi alat ukur dari negara lain yang kemudian diuji validitas dan reliabilitasnya. Menurut ITC (2017), dalam melakukan adaptasi alat ukur terdapat beberapa proses yang harus dilakukan yaitu precondition dengan mengajukan permission terhadap author, test conceptualization dengan memahami konstruk yang ingin diukur, proses forward translation, sintesis dan backward translation, expertjudgement, proses cognitive interview, dan dilanjutkan dengan melakukan tahap adminstrasi alat tes.

Adaptasi alat ukur work role performance ini diharapkan dapat mengukur perilaku kinerja karyawan yang merupakan sumber daya di dalam sebuah perusahaan di Indonesia. Berdasarkan pemaparan tersebut, penelitian ini bertujuan untuk mendapatkan hasil adaptasi terhadap budaya di Indonesia yang baik melalui beberapa langkah, yaitu melakukan uji content validity, uji menggunakan classical test theory, uji item response theory dan uji analisis konfirmatori.

\section{Metode}

\section{Partisipan}

Partisipan dalam penelitian ini yaitu karyawan sebanyak 370 orang. Partisipan dalam penelitian ini diambil dengan menggunakan teknik sampling incidental, yaitu teknik penentuan sampel yang dilakukan berdasarkan kebetulan/insidental bertemu 
dengan peneliti. Peneliti mencari partisipan dengan melakukan penyebaran informasi melalui media sosial serta meminta partisipan untuk mengisi link Google Form yang telah dibuat oleh peneliti. Partisipan dalam penelitian ini terdiri dari 180 partisipan berjenis kelamin laki-laki (48.6\%) dan 190 partisipan berjenis kelamin perempuan (51.4\%). Sebanyak 324 karyawan berusia 20 sampai dengan 40 tahun (88.5\%) dan 42 karyawan berusia 41 sampai dengan 60 tahun (11.5\%). Kemudian, sebanyak 66 karyawan bekerja pada perusahaan BUMN (17.8\%), 75 karyawan bekerja pada bidang pemerintahan (20.3\%), dan 229 karyawan bekerja pada perusahaan swasta (61.9\%).

\section{Prosedur penelitian}

Alat ukur work role performance yang dikembangkan oleh Griffin et al (2007) diadaptasi oleh peneliti melalui beberapa tahapan berdasarkan proses adaptasi yang direkomendasikan oleh ITC Guidelines (ITC, 2018). Dalam penelitian ini, tahapan yang dilakukan meliputi tahap persiapan, tahap translasi, tahap expert review, tahap cognitive interview, dan tahap pengambilan data.

Tahap pertama yaitu tahap persiapan. Pada tahapan ini, peneliti melakukan telaah konstruk dan meminta izin untuk melakukan adaptasi alat ukur work role performance terhadap author yang mengembangkannya, yaitu Griffin. Setelah mendapatkan izin dari author, peneliti melakukan translansi terhadap konstruk work role performance, yang dimulai dari translansi definisi, dimensi, dan subdimensi.
Tahapan translasi dilakukan melalui dua tahap yaitu forward dan backward translation. Pada tahap forward translation, alat ukur diterjemahkan dari bahasa Inggris ke dalam bahasa Indonesia oleh dua orang translator tersumpah. Dalam proses tersebut, translator menggunakan format translation yang disusun peneliti dan dikirimkan melalui $e$-mail. Setelah mendapatkan hasil dari forward translation, peneliti melakukan sintesis terhadap hasil translasi dari dua translator tersebut. Selanjutnya, tahapan translasi dilanjutkan ke tahap backward translation yang dilakukan oleh dua orang translator dari instansi tersumpah yaitu Anindyatrans \& Translindo. Pada tahapan ini, format translation juga diberikan kepada translator melalui e-mail.

Setelah tahapan translasi selesai, proses adaptasi dilanjutkan ke pengumpulan bukti validitas konten meliputi uji keterbacaan dan penelaahan terhadap kesesuaian butir untuk digunakan dalam konteks budaya perusahaan di Indonesia. Tahapan ini dilakukan melalui proses expert review terhadap tiga psikologi yang menguasai teori Psikologi Industri dan Organisasi. Format expert review dikirimkan melalui e-mail dan diisi secara independen oleh setiap ahli. Hasil dari expert review dihitung menggunakan Aiken's V sebagai bukti content validity.

Tahap adaptasi selanjutnya adalah tahapan cognitive interview. Tahapan ini dilakukan dengan tujuan untuk mendapatkan informasi apakah konstruk yang ingin diukur 
oleh peneliti dapat dipahami oleh partisipan. Dalam proses ini, peneliti memberikan kuesioner melalui Google Form kepada dua orang partisipan yang merupakan karyawan yang bekerja di kota Palembang. Setelah partisipan mengisi kuesioner, peneliti melakukan interview melalui aplikasi Whatsapp. Pertanyaan interview yang diberikan antara lain apakah pernyataan pada kuesioner mudah untuk dipahami, apakah ada pernyataan yang memiliki beberapa makna atau ambigu, apakah ada pernyataan yang berulang, untuk mengukur apakah kuesioner yang diberikan, dan apakah ada saran terhadap kuesioner. Hasil ini diolah secara kualitatif untuk mendapatkan informasi mengenai pemahaman partisipan terhadap kuesioner.

Selanjutnya, penulis melakukan pengambilan data atau uji coba terhadap 370 partisipan dengan kriteria yang telah ditentukan. Penelitian ini dilakukan dengan menggunakan Google Form. Dalam Google Form tersebut tercantum informasi singkat tentang tujuan penelitian, kesukarelaan, dan penjelasan mengenai komitmen dari peneliti untuk menjaga kerahasiaan data dari partisipan. Setelah partisipan menyatakan kesediaan, partisipan mengisi skala work role performance berbahasa Indonesia hasil perbaikan dari tahapan sebelumnya. Dalam proses ini, partisipan juga mengisi informasi mengenai data demografis mereka. Pengambilan data ini dilakukan selama dua minggu antara tanggal 15 Oktober sampai dengan 28 Oktober 2020.

\section{Pengukuran}

\section{Skala Work Role Performance}

Alat ukur Work Role Performance yang digunakan dalam penelitian ini disusun berdasarkan teori Griffin et al (2007). Penulis melakukan adaptasi terhadap 27 butir pernyataan yang dikembangkan dari Griffin et al (2007) yang terdiri atas dimensi adaptivity ( 9 butir), dimensi proactivity (9 butir), dan dimensi favourable ( 9 butir). Penulis menggunakan kategori jawaban yang biasa digunakan untuk mengukur perilaku atau intensi berdasarkan Azwar (2016), yaitu hampir tidak pernah, sangat jarang, kadangkadang, sangat sering, dan hampir selalu.

\section{Metode analisis data}

\section{Pengujian content validity}

Validitas konten dapat diperoleh melalui validasi terhadap butir-butir dalam tes yang bertujuan untuk mengestimasi kelayakan butirbutir dalam tes guna mewakili komponen atau sejauh mana kesesuian butir-butir dari konstruk yang diukur (Azwar, 2015). Salah satu cara yang dapat digunakan untuk melakukan validasi konten adalah melalui expertjudgement (Sugiyono, 2016). Hasil penilain expert judgement dihitung menggunakan formula Aiken's V (Aiken, 1985). Melalui formula ini, content-validity coefficient dihitung berdasarkan hasil penilaian panel ahli sebanyak $n$ orang terhadap suatu butir mengenai sejauh mana butir tersebut mewakili konstruk yang diukur. Penilaian dilakukan dengan cara 
memberikan angka di antara 1 (sangat tidak relevan) sampai dengan 4 (sangat relevan). Syarat batas koefisien Aiken's V untuk 5 skala rating adalah .75 dengan probabilitas .41 (Azwar, 2016). Gambar 1 menyajikan formula yang digunakan.

\section{Gambar 1}

Formulasi Aiken's V (Aiken, 1985)

$$
\mathrm{V}=\mathrm{Ss} /[\mathbf{n}(\mathbf{c}-1)]
$$

Catatan. lo = Angka penilaian validitas yang terendah (dalam hal ini :1); $\mathrm{c}=$ Angka penilaian validitas yang tertinggi (dalam hal ini: 4); $r$ = Angka yang diberikan oleh seorang penilai (expert review); s = r - lo

\section{Pengujian berdasarkan Classical Test Theory (CTT)}

Pendekatan model CTT dalam penelitian ini digunakan untuk menguji reliabilitas konstruk berdasarkan teknik konsistensi internal Alpha Cronbach. Kriteria dari Kaplan \& Saccuzo (2005), digunakan untuk mengevaluasi tingkat reliabilitas dari alat ukur dalam penelitian. Berdasarkan kriteria tersebut, nilai Alpha Cronbach lebih besar sama dengan .70 berarti alat ukur dapat diandalkan, dan apabila nilai Alpha Cronbach lebih kecil dari .70 menunjukkan bahwa alat ukur tidak dapat diandalkan. Selain itu, corrected item-total correlation juga dianalisis untuk mengevaluasi daya pembeda. Kriteria dari Azwar (1999) digunakan untuk mengevaluasi daya pembeda. Butir yang dengan corrected item-total minimal sebesar .30 menunjukkan bahwa butir memiliki datya pembeda yang memuaskan (Azwar, 2016). Perangkat lunak SPSS versi 25 for Macintosh digunakan dalam melakukan analisis CTT.

\section{Pengujian Rasch's Model}

Pengujian reliabilitas item response theory (IRT) dianalisis dengan menggunakan bantuan software Winstep dengan pendekatan Rasch model. Analisis ini dilakukan untuk mengatasi keterbatasan pendekatan CTT yang sangat tergantung pada populasi. Melalui pendekatan Rasch model, informasi pada setiap butir bisa didapatkan berdasarkan interaksi abilitas responden terhadap butir-butir soal yang menyusun dan tidak akan bergantung pada populasi. Dalam penelitian ini, reliabilitas person dan reliabilitas butir dianalisis untuk mengevaluasi keterandalan butir-butir hasil adaptasi. Menurut Sumintono et al (2014) kriteria person and item measurement reliability yang baik adalah yaitu nilai $<.67$ dikategorikan poor; .67 - .80 dikategorikan fair; .89 - .90 dikategorikan good; .91 - .94 dikategorikan very good; dan $>.94$ dikategorikan excellent. 


\section{Pengujian validitas dengan Confirmatory Factor Analysis (CFA)}

Validitas mengenai struktur internal dari alat ukur work role performance dalam penelitin ini diuji dengan menggunakan CFA. Tujuan dari CFA adalah untuk mengonfirmasi sejauh mana butir dari tes yang diadaptasi memang mengukur satu konstruk tunggal, yaitu work role performance. Dalam sebuah alat ukur psikologi, semua butirnya harus mengukur hanya satu hal saja yaitu konstruk yang hendak diukur (Umar \& Nisa, 2020).

Menurut Umar (2012) terdapat beberapa logika dasar CFA, sebagai berikut:

1. Bahwa ada sebuah konsep atau trait berupa kemampuan yang didefinisikan secara operasional sehingga dapat disusun pertanyaan atau pernyataan untuk mengukurnya. Kemampuan ini disebut faktor, sedangkan pengukuran terhadap faktor ini dilakukan melalui analisis terhadap respon atas butir-butir-nya.

2. Secara teoretis, seluruh butir hanya mengukur satu faktor saja. Artinya keseluruhan tes bersifat unidimensional.

3. Dengan data yang tersedia dapat diprediksi matriks korelasi antar-butir yang seharusnya diperoleh jika memang unidimensional. Matriks korelasi ini disebut sigma (Ó), kemudian dibandingkan dengan matriks dari data empiris, yang disebut matriks S. Jika teori tersebut benar (unidimensional) maka tidak ada perbedaan antara matriks Ó dan matriks S, atau bisa juga dinyatakan dengan Ó - $\mathrm{S}=0$.
4. Pernyataan tersebut dijadikan hipotesis nihil yang kemudian diuji dengan chi-square. Jika hasil chi-square tidak signifikan $(p>.05)$, hipotesis nihil tersebut "tidak ditolak". Artinya hipotesis unidimensionalitas tentang alat ukur dapat diterima (hanya mengukur satu faktor saja). Tetapi jika chi-square signifikan $(p<.05)$, modifikasi terhadap model dapat dilakukan dengan cara membebaskan parameter berupa korelasi di antara kesalahan pengukuran.

5. Setelah diperoleh model fit dengan data, langkah selanjutnya adalah menguji apakah koefisien muatan faktor untuk setiap butir signifikan atau tidak mengukur apa yang hendak di ukur. Ini dilakukan dengan menggunakan uji-t. Pada penelitian ini, penulis menggunakan taraf kepercayaan $95 \%$ sehingga butir yang dikatakan signifikan adalah butir yang memiliki nilai $\mathrm{t}$ lebih dari $1.96(t>1.96)$. Jika hasil uji-t tidak signifikan maka butir tersebut tidak mengukur apa yang hendak diukur. Apabila diperlukan, butir demikian dieliminasi.

Pengujian hipotesis pada CFA tidak dapat dilakukan hanya dengan menggunakan chi-square, karena terkadang chi-square terlalu sensitif terhadap beberapa hal, salah satunya adalah ukuran sampel. Jika sampel yang digunakan terlalu banyak, chi-square akan cenderung signifikan (Tanaka, 1993). Oleh karena itu, dalam penelitian ini kecocookan model dievaluasi menggunakan nilai Root Mean Square Error of Approximation (RMSEA) yang 
tidak sensitif terhadap ukuran sampel. Menurut Hair Jr et al (2010) memiliki nilai RMSEA berkisar pada .05 - .08 maka dapat termasuk ke dalam kategori good fit. Selain itu, dapat dilihat berdasarkan nilai CFI, menurut ketika suatu data memiliki nilai CFI lebih besar sama dengan .90 (CFI $\boldsymbol{e}^{\prime .90)}$ menunjukkan kriteria model pengukuran good fit.

Dalam penelitin ini, analisis CFA dilakukan untuk mencari pola multidimensional butir dari work role performance sehingga bisa diperoleh kelompok butir yang mengukur work role performance pada karyawan. Analisis CFA dilakukan pada dua level, yaitu level pertama analisis CFA pada setiap dimensi. Pada level ini, pengujian model dilakukan menggunakan model first order untuk mengonfirmasi apakah 9 butir pada setiap dimensi mengukur konstruk pada tingkat dimensi. Pada level kedua, analisis CFA dilakukan secara bersama-sama menggunakan model second order. Pada tahapan yang ini, peneliti membuat model pengukuran bertingkat meliputi tiga dimensi work role performance sebagai latent variable dengan 9 butir pada masing-masing dimensi sebagai observed variabel. Semua analisis CFA pada penelitian ini dilakukan menggunakan LISREL 8.8.

\section{Hasil}

\section{Hasil pengujian validitas konten, CTT dan Rasch's model}

Hasil perhitungan validitas konten dan reliabilitas alat ukur, baik menggunakan CTT maupun Rasch disajikan pada tabel 1 . Berdasarkan tabel dapat dilihat bahwa perhitungan Aiken's V menunjukkan bahwa semua dimensi termasuk ke dalam kategori valid dengan nilai rata-rata $V$ sebesar .87 untuk dimensi proficiency dan dimensi adaptivity, dan untuk dimensi proactivity dengan nilai sebesar .91. Nilai koefisian di atas .75 menunjukkan bahwa butir-butir hasil adaptasi pada setiap dimensi relevan untuk mengukur konstruk work role performance.

Berdasarkan uji CTT diperoleh bahwa alat ukur work role performance hasil adaptasi memiliki reliabilitas Alpha Cronbach .936. Hal ini menunjukkan bahwa sebesar 94\% dari varians observed score merupakan varians true score dan hanya $6 \%$ sisanya merupakan varians error yang bisa disebabkan oleh content sampling error. Oleh karena itu, dapat dikatakan bahwa alat ukur work role performance hasil adaptasi dapat diandalkan. Perhitungan terhadap corrected-item total correlation pada 27 butir pertanyaan bernilai antara .397 - .696 menunjukkan bahwa butir-butir hasil adaptasi mampu membedakan partisipan berdasarkan karakteristik work role performance mereka. 
Pada tabel 1, disajikan juga hasi perhitungan reliabilitas melalui Rasch's model menunjukkan reliabilitas person sebesar .87 (kriteria good) dan reliabilitas butir sebesar
.98 (kriteria very good). Hal ini menunjukkan bahwa alat ukur hasil adaptasi dapat dipercaya untuk digunakan sebagai alat pengumpul data.

\section{Tabel 1}

Hasil Analisis CTT dan Rasch Model

\begin{tabular}{lcccl}
\hline \multicolumn{1}{c}{ Konstruk } & $\begin{array}{c}\text { Cronbach's } \\
\alpha\end{array}$ & $\begin{array}{c}\text { Person } \\
\text { Reliability }\end{array}$ & Item Reliability & Kategori \\
\hline $\begin{array}{l}\text { Work Role } \\
\text { Performance }\end{array}$ & .936 & .870 & .980 & $\begin{array}{l}\text { Dapat } \\
\text { diandalkan }\end{array}$ \\
\hline Catatan. $\mathrm{N}=27$ & & & &
\end{tabular}

\section{Tabel 2}

Hasil Analisis Validitas Konten

\begin{tabular}{lccl}
\hline \multicolumn{1}{c}{ Dimensi } & $\begin{array}{c}M \\
\text { Aiken's }\end{array}$ & Cronbach's $\alpha$ & Kategori \\
\hline Proficiency & .870 & .812 & $\begin{array}{l}\text { Dapat } \\
\text { diandalkan } \\
\text { Dapat } \\
\text { diandalkan } \\
\text { Daptivity }\end{array}$ \\
Proactivity & .870 & .850 & $\begin{array}{l}\text { Dat } \\
\text { diandalkan }\end{array}$ \\
\hline
\end{tabular}

Catatan. $n=9$

\section{Hasil pengujian validitas dengan CFA}

\section{a. Dimensi Proficiency}

Peneliti menguji apakah butir yang diadaptasi bersifat unidimensional dengan mengukur faktor proficiency. Pada tahap analisis CFA yang dilakukan diperoleh bahwa model tidak fit, dengan chi-square $=157.69, d f$ $=27, p=.000$, RMSEA $=.114, \mathrm{CFI}=.93$. Oleh karena itu peneliti melakukan modifikasi terhadap model ini, yaitu dengan membebaskan korelasi antar kesalahan pengukuran. Setelah dilakukan modifikasi, diperoleh model fit dengan nilai chi-square = 31.12, $d f=20, p=.000$, RMSEA $=.045, \mathrm{CFI}=$ 99. Hal ini menunjukkan model ini hanya terdapat satu faktor dapat diterima, diseluruh butir hanya mengukur satu faktor saja. Hasil CFA untuk dimensi proficiency disajikan pada Gambar 2. 


\section{Gambar 2}

\section{Hasil CFA Dimensi Proficiency}

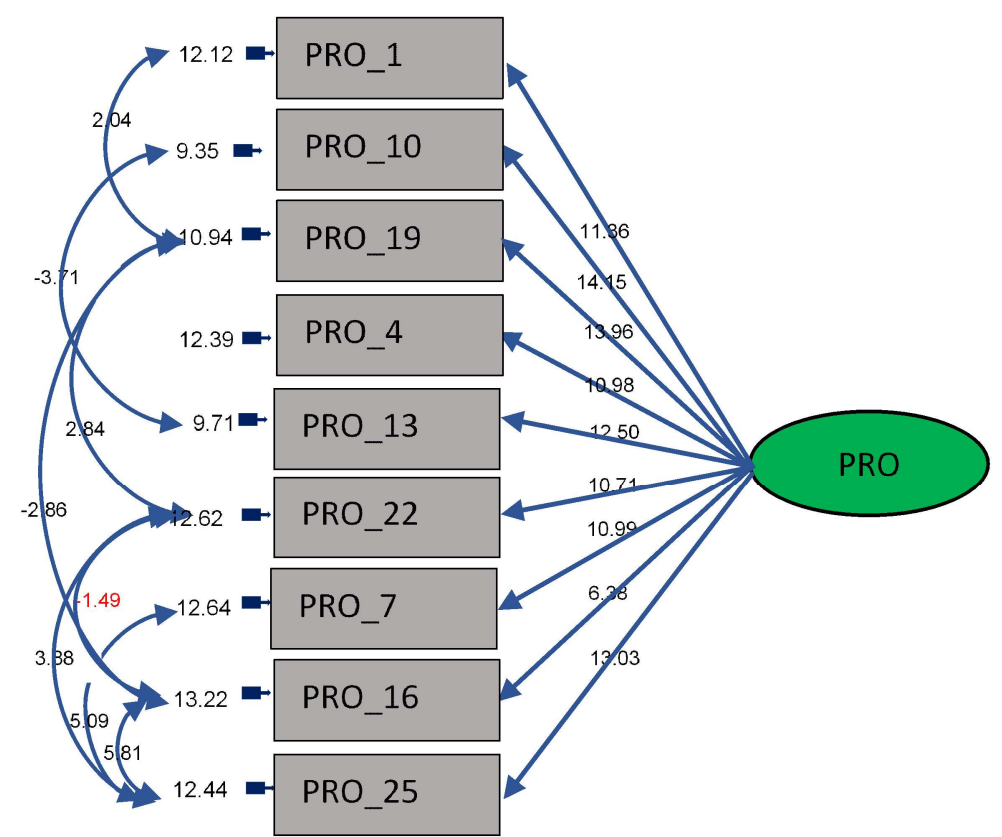

Chi-Square $=21.43, \mathrm{df}=18, \mathrm{P}$-value $=0.02564, \mathrm{RMSEA}=0.045$

Selanjutnya, peneliti ingin melihat apakah setiap butir mengukur faktor yang hendak diukur. Pengujian dilakukan dengan melihat nilai $t$ dari setiap muatan faktor. Menurut Umar (2012a) nilai $t$ (t-value) dikatakan valid apabila bernilai lebih dari $1.96(t>1.96)$. Koefisien muatan faktor untuk dimensi proficiency yang dapat dilihat pada tabel 3.

\section{Tabel 3}

Standardized Factor Loading Dimensi Proficiency

\begin{tabular}{lcccc}
\hline \multicolumn{1}{c}{ Aitem } & $\lambda$ & $S E$ & $t$ & $\begin{array}{c}\text { Jumlah Korelasi } \\
\text { Kesalahan Pengukuran }\end{array}$ \\
\hline Nomor 1 & .34 & .03 & 11.36 & 2 \\
Nomor & .43 & .03 & 14.15 & 3 \\
10 & .39 & .03 & 13.96 & 0 \\
Nomor & & & & 1 \\
19 & .38 & .03 & 10.98 & 3 \\
Nomor 4 & .47 & .03 & 12.50 & 1 \\
Nomor & .35 & .03 & 10.71 & 3 \\
13 & .38 & .04 & 10.99 & 3 \\
Nomor & .34 & .05 & 6.38 & \\
22 & & & & \\
Nomor 7 & .44 & .04 & 13.03 & \\
Nomor & & & & \\
16 & & & & \\
Nomor & .35 & & & \\
25 & & & & \\
\hline
\end{tabular}


Berdasarkan tabel 3, dapat dilihat bahwa butir memiliki nilai $t$ di atas $1.96(p<.05)$, yang menunjukkan bahwa tiap butir atau berkontribusi secara signifikan untuk mengukur dimensi proficiency.

\section{a. Dimensi Adaptivity}

Peneliti menguji apakah butir yang ada bersifat unidimensional dengan mengukur faktor adaptivity. Dari hasil awal analisis CFA yang dilakukan diperoleh model yang tidak fit, dengan chi-square $=115.58, d f=27, p=.000$, RMSEA $=.11, \mathrm{CFI}=.96$. Oleh karena itu peneliti melakukan modifikasi terhadap model ini, yaitu dengan membebaskan korelasi antar kesalahan pengukuran. Setelah dilakukan modifikasi, diperoleh model fit dengan nilai chi-square $=$ 29.40, $d f=20, p=.000$, RMSEA $=.045$, CFI $=.99$. Hal ini menunjukkan model ini hanya terdapat satu faktor dapat diterima. Adapun hasil CFA dimensi adaptivity disajikan pada gambar 3 .

\section{Gambar 3}

Hasil CFA Dimensi Adaptivity

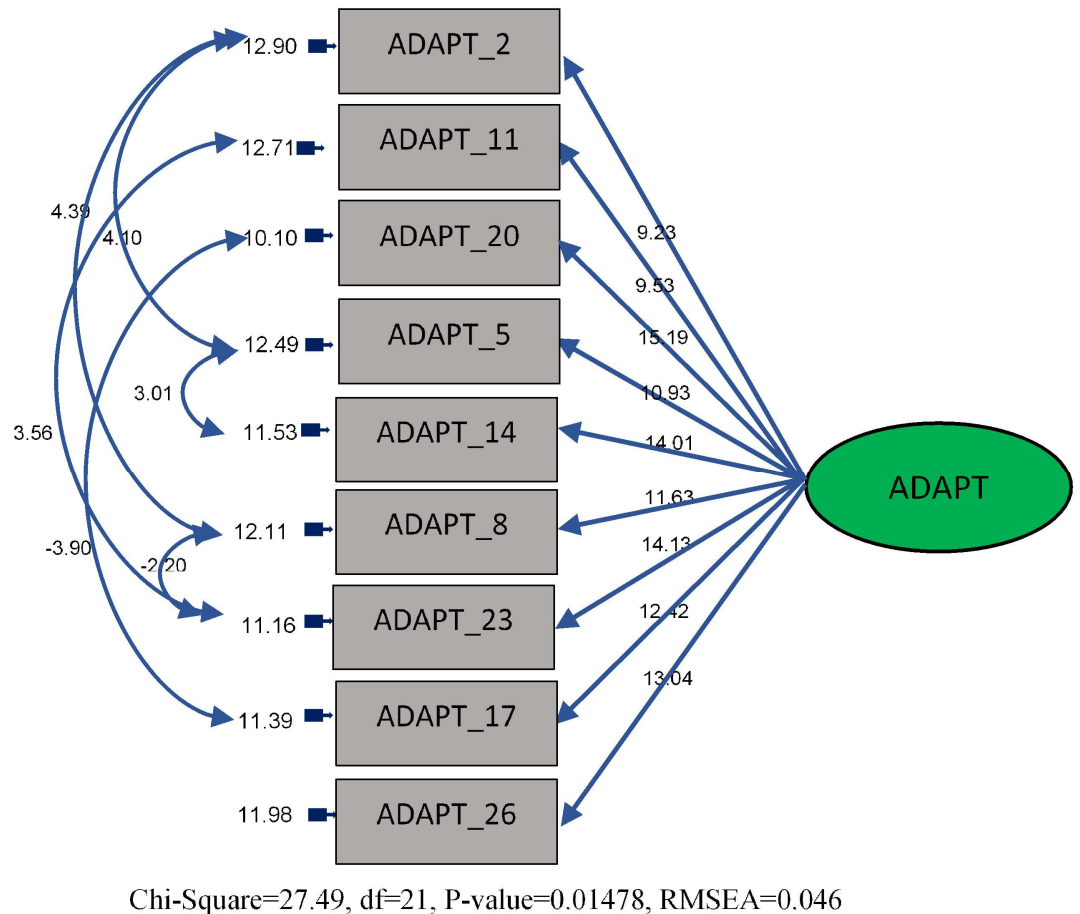

Selanjutnya, peneliti ingin melihat apakah setiap butir mengukur faktor yang hendak diukur. Pengujian dilakukan dengan melihat nilai $t$ dari setiap muatan faktor. Menurut (Umar, 2012a) nilai $t(t$-value) dikatakan valid apabila bernilai lebih dari $1.96(t>1.96)$. Koefisien muatan faktor untuk dimensi proficiency yang dapat dilihat pada tabel 4 . 


\section{Tabel 4}

Standardized Factor Loading Dimensi Adaptivity

\begin{tabular}{lcccc}
\hline \multicolumn{1}{c}{ Aitem } & $\lambda$ & $S E$ & $t$ & $\begin{array}{c}\text { Jumlah Korelasi } \\
\text { Kesalahan Pengukuran }\end{array}$ \\
\hline Nomor 2 & .49 & .04 & 9.23 & 2 \\
Nomor 11 & .50 & .04 & 9.53 & 1 \\
Nomor 20 & .74 & .03 & 15.19 & 1 \\
Nomor 5 & .56 & .04 & 10.93 & 2 \\
Nomor 14 & .69 & .03 & 14.01 & 1 \\
Nomor 23 & .69 & .04 & 11.63 & 2 \\
Nomor 8 & .60 & .03 & 14.13 & 1 \\
Nomor 17 & .64 & .04 & 12.42 & 0 \\
Nomor 26 & .65 & .04 & 13.04 & 2 \\
\hline
\end{tabular}

Berdasarkan tabel 4, dapat dilihat bahwa semua butir memiliki nilai $t$ di atas $1.96(p<$ $.05)$, yang artinya berdasarkan uji signifikansi koefisien regresi tiap butir dinyatakan valid atau berkontribusi signifikan terhadap pengukuran dimensi adaptivity.

\section{a. Dimensi Proactivity}

Peneliti menguji apakah butir yang ada bersifat unidimensional dengan mengukur faktor proactivity. Dari hasil awal analisis CFA yang dilakukan diperoleh model yang tidak fit, dengan chi-square $=115.58, d f=27, p=.000$, RMSEA $=$ $.11, \mathrm{CFI}=.99$. Oleh karena itu peneliti melakukan modifikasi terhadap model ini, yaitu dengan membebaskan korelasi antar kesalahan pengukuran. Setelah dilakukan modifikasi, diperoleh model fit dengan nilai chi-square $=29.40$, $d f=20, p=.000, \mathrm{RMSEA}=.045, \mathrm{CFI}=1.00$. Hal ini menunjukkan model ini hanya terdapat satu faktor dapat diterima, diseluruh butir hanya mengukur satu faktor saja. Hasil CFA untuk dimensi proactivity dapat dilihat pada Gambar 4.

\section{Gambar 4}

Hasil CFA Dimensi Proacivity

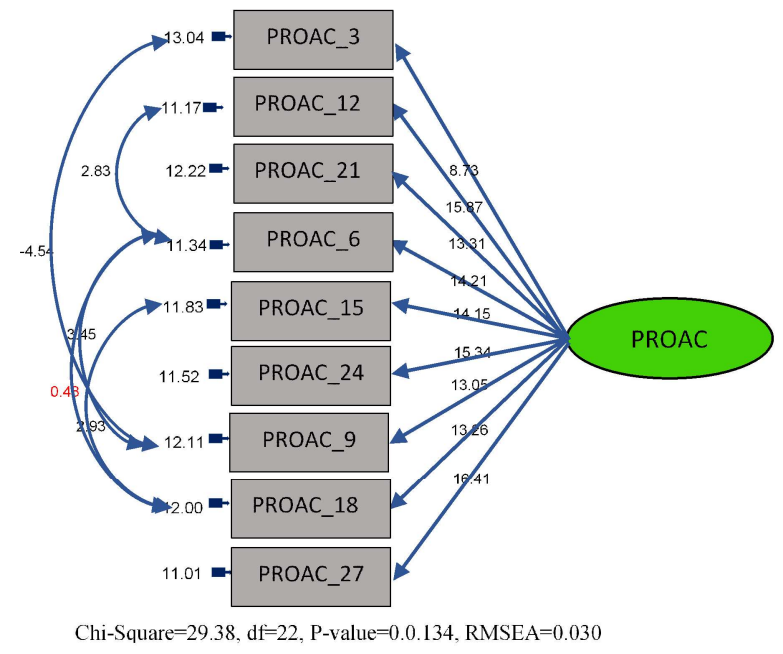


Hasil perhitungan untuk standardized factor loading disajikan pada tabel 5. Pada tabel 5 dapat dilihat bahwa semua butir memiliki nilai $t$ di atas $1.96(p<.05)$, menunjukkan bahwa setiap butir dinyatakan valid atau berkontribusi signifikan untuk mengukur dimensi proactivity.

\section{Tabel 5}

Standardized Factor Loading Dimensi Proactivity

\begin{tabular}{lcccc}
\hline \multicolumn{1}{c}{ Aitem } & $\lambda$ & $S E$ & $t$ & $\begin{array}{c}\text { Jumlah Korelasi } \\
\text { Kesalahan Pengukuran }\end{array}$ \\
\hline Nomor 3 & .28 & .03 & 8.73 & 1 \\
Nomor 12 & .58 & .04 & 15.87 & 1 \\
Nomor 21 & .58 & .04 & 13.31 & 0 \\
Nomor 6 & .63 & .04 & 14.21 & 3 \\
Nomor 15 & .63 & .04 & 14.15 & 1 \\
Nomor 24 & .53 & .03 & 15.34 & 0 \\
Nomor 9 & .68 & .05 & 13.05 & 3 \\
Nomor 18 & .62 & .05 & 13.28 & 2 \\
Nomor 27 & .64 & .04 & 16.41 & 0 \\
\hline
\end{tabular}

\section{Second order CFA}

Hasil awal CFA didapati nilai chisquare sebesar 1299.06, $d f=(p<.05)$, RMSEA $=.10$. Hal ini menunjukkan model awal second order dinyatakan tidak fit. Oleh karena itu penulis melakukan modifikasi pada model dengan cara membebaskan korelasi kesalahan pengukuran pada butir, sehingga diperoleh hasil seperti pada gambar 5. 


\section{Gambar 5}

Hasil Second Order CFA

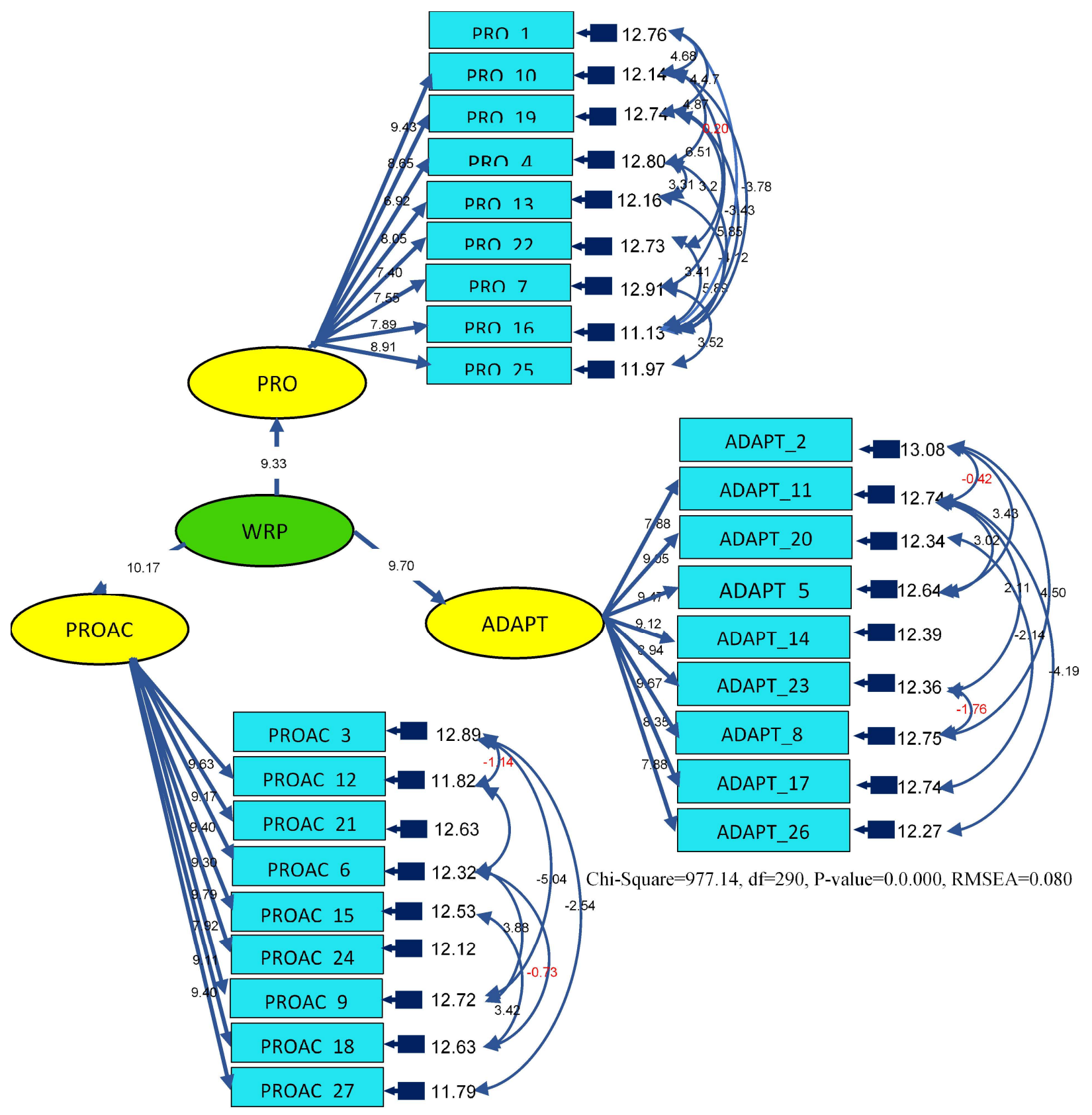

Berdasarkan gambar 5, dapat dilihat bahwa model fit di atas memiliki nilai chisquare sebesar 997.14, $d f=290, p<.05$, RMSEA $=.080$. Hasil tersebut menunjukkan bahwa konstruk ini cukup fit dikarenakan menurut Hair Jr et al (2010) memiliki nilai RMSEA berkisar pada .05 - .08 maka dapat termasuk ke dalam kategori good fit. Selain itu, dapat dilihat berdasarkan nilai CFI, menurut ketika suatu data memiliki nilai CFI lebih besar sama dengan .90 (CFI $\boldsymbol{e}^{\prime} .90$ ) menunjukkan kemampuan model telah baik dalam hal mencocokkan data (good 
fit). Dalam penelitian ini, nilai CFI sebesar .96 (CFI > .90), maka dapat dikatakan data ini memiliki nilai yang good fit. Namun setelah itu, perlu dilihat nilai $t$ pada setiap butir untuk melihat signifikansinya.

Pada tabel 6, disajikan juga hasil pengukuran standardized factor analysis dapat mengetahui nilai $t$ pada setiap butir untuk melihat signifikasi. Nilai yang diharapkan pada $t$ pada masing-masing butir sebesar $>1.96$ untuk dapat dinyatakan signifikan. Berdasarkan hasil dari perhitungan signifikasi (lamda) pada setiap butir alat ukur WRP-S didapatkan seluruh butir telah memenuhi syarat $(t>1.96)$. Oleh karena itu, dapat disimpulkan bahwa seluruh butir pada alat ukur ini sudah memiliki validitas yang baik.

Tabel 6

Standardized Factor Analysis pada CFA Second Order

\begin{tabular}{lcccr}
\hline Dimensi/Aitem & $\lambda$ & $S E$ & $t$ & $\begin{array}{r}\text { Jumlah } \\
\text { Kesalahan }\end{array}$ \\
\hline Proficiecy & & & & \\
Aitem 1 & .36 & - & - & \\
Aitem 10 & .39 & .04 & 9.43 & \\
Aitem 19 & .33 & .04 & 8.65 & \\
Aitem 4 & .35 & .05 & 6.92 & \\
Aitem 13 & .45 & .06 & 8.05 & \\
Aitem 22 & .38 & .05 & 7.40 & \\
Aitem 7 & .42 & .06 & 7.55 & \\
Aitem 16 & .71 & .09 & 7.89 & \\
Aitem 25 & .60 & .07 & 8.91 & \\
& & & & \\
Adaptivity & & & & \\
Aitem 2 & .39 & - & - & \\
Aitem 11 & .42 & .05 & 7.88 & \\
Aitem 20 & .47 & .05 & 9.05 & \\
Aitem 5 & .55 & .06 & 9.47 & \\
Aitem 14 & .50 & .05 & 9.12 & \\
Aitem 23 & .45 & .05 & 8.94 & \\
Aitem 8 & .46 & .05 & 9.67 & \\
Aitem 17 & .49 & .06 & 8.35 & \\
Aitem 26 & .58 & .06 & 9.02 & \\
Proactivity & & & & \\
Aitem 3 & .29 & - & - & \\
Aitem 12 & .52 & .05 & 9.63 \\
Aitem 21 & .52 & .06 & 9.17 \\
Aitem 6 & .56 & .06 & 9.40 \\
Aitem 15 & .56 & .06 & 9.30 \\
Aitem 24 & .48 & .05 & 9.79 \\
Aitem 9 & .59 & .07 & 7.92 & \\
Aitem 18 & .55 & .06 & 9.11 & \\
Aitem 27 & .57 & .06 & 9.40 & \\
Proficiency & .84 & .09 & 9.33 & \\
Adaptivity & .88 & .09 & 9.70 & \\
Proactivity & 1.05 & .10 & 10.17 & \\
\hline & & & & \\
\hline
\end{tabular}




\section{Pembahasan}

Penelitian ini bertujuan untuk mengevaluasi validitas dan reliabilitas alat ukur work role performance dalam bahasa Indonesia. Aiken's V digunakan untuk mengevaluasi validitas konten alat ukur. Kemudian CTT dan analisis Rasch digunakan untuk mengevaluasi realibilitas dari alat ukur. Classical test theory digunakan untuk melihat Alpha Cronbach sebagai koefisien konsistensi internal sebuah konstruk dan dimensi dari reliabilitas sebuah alat ukur. Setelah melakukan pengujian terhadap alat ukur work role performance, didapatkan nilai koefisien alpha pada reliabilitas yang tergolong tinggi, baik pada konstruk secara keseluruhan ataupun per dimensi. Selain itu, analisis corrected item-total correlation menunjukkan daya pembeda yang baik. Hasil tersebut menunjukkan bahwa kualitas butir yang diukur tergolong baik dan alat ukur yang diadaptasi dapat mengukur konstruk secara konsisten.

Pada alat ukur yang diadaptasi ini tidak terdapat butir yang dieliminasi. Dengan demikian, hasil adaptasi WRP-S ke dalam bahasa Indonesia memiliki jumlah butir yang sama dengan alat ukur aslinya, yaitu sebanyak 27 butir. Pembuktian melalui confirmatory factor analysis menunjukkan bahwa pada populasi Indonesia, model pengukuran work role performance dapat direpresentasikan dari tiga faktor yaitu proficiency, adaptivity, dan proactivity.
Implikasi dari hasil analisis CFA pada penelitian ini menunjukkan bahwa WRP-S dapat digunakan untuk membantu dalam menjelaskan perilaku kerja karyawan di Indonesia berupa peran mereka untuk mengkontribusikan diri pada tingkat individu, tim, dan organisasi dalam bentuk perilaku proficiency, adaptivity, dan proactivity. Selain itu, dalam penelitian ini terdapat kekurangan yaitu jumlah responden yang masih terbatas untuk dapat merepresentasikan jumlah karyawan yang ada di Indonesia. Kekurangan yang terdapat pada penelitian ini dapat diperbaiki pada penelitian selanjutnya.

\section{Simpulan}

Berdasarkan uji statistik yang telah dilakukan menunjukkan bahwa tidak ada butir yang dieliminasi, maka dapat dikatakan alat ukur WRP-S yang tersusun dari 27 butir dapat dikatakan reliabel dengan nilai 936 dan secara umum butir penyusunnya memiliki daya pembeda yang baik dengan nilai corrected itemtotal correlation berkisar antara .397 sampai dengan .696. Hal ini menunjukkan bahwa alat ukur hasil adaptasi memiliki konsistensi internal yang kuat dan butir penyusun dapat mengukur konstruk work role performance secara baik. Hasil dari uji CFA juga menghasilkan model alat ukur yang mencapai kriteria goodness of fit untuk mengukur work role performance dengan tetap mempertahankan keseluruhan butir penyusunnya. Nilai RMSEA yang didapatkan yaitu .080 dan nilai CFI sebesar .960 . 
Selanjutnya, melalui uji model Rasch juga didapatkan konsistensi alat ukur berupa person reliability sebesar .87 dan item reliability sebesar 98 yang berarti hasil adaptasi work role performance ini reliabel.

Atas pertimbangan seluruh hasil uji yang telah dilakukan terhadap alat ukur work role performance yang telah diadaptasi oleh peneliti, maka alat ukur WRP-S ini dapat dinilai sebagai alat ukur yang reliabel atau memadai digunakan untukan untuk mengukur intensi dari perilaku performance pada karyawan yang ada di dalam perusahaan, baik pada tingkat staf dan manajerial di Indonesia, serta dapat digunakan untuk penelitian selanjutnya.

\section{Saran}

Mengacu pada masih terdapat beberapa kekurangan dari penelitian ini, maka peneliti mengusulkan beberapa saran yang dapat digunakan untuk perbaikan, pengembangan, atau adaptasi lebih lanjut di penelitian-penelitian berikutnya dengan menggunakan konsep yang sama. Adapun saran yang diusulkan oleh peneliti adalah mempertimbangkan jumlah sampel agar mendapatkan hasil CFA yang lebih stabil serta nilai $p$ menjadi lebih besar dari 05 . Selain itu, dalam mempertimbangkan jumlah sampel yaitu alat ukur WRP-S agar dapat merepresentasikan karyawan yang ada di Indonesia.

\section{Referensi}

Aiken, L. R. (1985). Psychological testing and assessment (5th ed.). Allyn and Bacon Inc.
Azwar, S. (1999). Reliabilitas dan validitas. Sigma Alpha.

Azwar, S. (2015). Dasar-dasar psikometrika (2nd ed.). Pustaka Belajar.

Azwar, S. (2016). Penyusunan skala psikologi (2nd ed.). Pustaka Belajar.

Fulmer, I. S., \& Ployhart, R. E. (2014). "Our most important asset." Journal of Management, 40(1), 161-192. https://doi.org/ $10.1177 / 0149206313511271$

Griffin, M. A., Neal, A., \& Parker, S. K. (2007). A new model of work role performance: Positive behavior in uncertain and interdependent contexts. Academy of Management Journal, 50(2), 327-347. h t tp s: / / doi.org/10.5465/ amj.2007.24634438

Hair Jr, J. F., Babin, B. J., Black, W. C., Anderson, R. E., \& Tatham, R. L. (2010). Multivariate data analysis (7th ed.). Pearson Education.

ITC. (2018). ITC guidelines for translating and adapting tests (second edition). International Journal of Testing, 18(2), 101-134. https://doi.org/10.1080/ 15305058.2017.1398166

Jundt, D. K., Shoss, M. K., \& Huang, J. L. (2015). Individual adaptive performance in organizations: A review. Journal of Organizational Behavior, 36(S1), S53S71.https://doi.org/10.1002/job.1955

Kaplan, R. M., \& Saccuzo. (2005). Psychological testing: Principles, application, and issues (6th ed.). Thompson Wadsworth.

Katz, D., \& Kahn, R. (1978). The social psychology of organization behavior (2nd ed.). Wiley.

Murphy, P., \& Jackson, S. (1999). Managing work-role performance: Challenges for 21 st century organization and employees. In In D. R. Ilgen \& E.D. Pulakos (Eds) The changing nature of work performance (pp. 325-365). file:/// Users/bellasaviera/Downloads/Murphy dan Jackson, 1999.pdf 
Priyono. (2010). Manajemen sumber daya manusia. Zifatama Publisher.

Shmailan, A. S. (2016). The relationship between job satisfaction, job performance and employee engagement: An explorative study. Issues in Business Management and Economics, 4(1), 1-8. https://doi.org/http://dx.doi.org/ 10.15739/IBME.16.001

Sugiyono. (2016). Metode penelitian kuantitatif, kualitatif, dan R\&D (24th ed.). Alfabeta.

Sumintono, B., Widhiarso, W., \& Mada, U. G. (2014). Aplikasi model Rasch untuk penelitian ilmu-ilmu sosial. November. file:///Users/bellasaviera/Downloads/ Sumintono dan Widhiarso, 2014.pdf

Tanaka, J. S. (1993). Multifaceted conceptions of fit in structural models. Testing Structural Equation Models, 10-40.

Umar, J. (2012a). Confirmatory factor analysis: Bahan ajar perkuliahan. Fakultas Psikologi UIN Jakarta.
Umar, J. (2012b). Peran pengukuran dan analisis stasitisik dalam penelitian psikologi. JP3I (Jurnal Pengukuran Psikologi Dan Pendidikan Indonesia), I(1). file:///Users/bellasaviera/ Downloads/Umar, 2012.pdf

Umar, J., \& Nisa, Y. F. (2020). Uji validitas konstruk dengan CFA dan pelaporannya. Jurnal Pengukuran Psikologi Dan Pendidikan Indonesia, 9(2), 1-11. http:// journal.uinjkt.ac.id/index.php/jp3i/ article/view/16964

Viswesvaran, C., \& Ones, D. S. (2000). Perspectives on models of job performance. International Journal of Selection and Assessment, 8(4), 216226. https://doi.org/10.1111/14682389.00151

Received 31 December 2020 Revised 13 April 2021 Accepted 31 July 2021 